\title{
Thoughts and acts of self-harm, and suicidal ideation, in online gamblers
}

\section{Joanne Lloyd, Keith Hawton, William H. Dutton, John R. Geddes, Guy M. Goodwin \& Robert D. Rogers}

To cite this article: Joanne Lloyd, Keith Hawton, William H. Dutton, John R. Geddes, Guy M. Goodwin \& Robert D. Rogers (2016): Thoughts and acts of self-harm, and suicidal ideation, in online gamblers, International Gambling Studies, DOI: 10.1080/14459795.2016.1214166

To link to this article: http://dx.doi.org/10.1080/14459795.2016.1214166

曲 Published online: 05 Aug 2016.

Submit your article to this journal $₫$

Џ Article views: 21

View related articles $\sqsubset$

View Crossmark data $\nearrow$ 


\title{
Thoughts and acts of self-harm, and suicidal ideation, in online gamblers
}

\author{
Joanne Lloyd ${ }^{a}$, Keith Hawton ${ }^{b}$, William H. Dutton, John R. Geddes ${ }^{b}$, Guy M. Goodwin ${ }^{b}$ \\ and Robert D. Rogers ${ }^{\mathrm{d}}$
}

aSchool of Psychology, Sport and Exercise, Staffordshire University, Science Centre, Stoke on Trent, UK; bepartment of Psychiatry, Warneford Hospital, University of Oxford, Oxford, UK; 'Quello Center, Michigan State University, East Lansing, USA; dSchool of Psychology, Bangor University, Gwynedd, UK

\begin{abstract}
Gambling problems have been linked to suicidal ideation and enhanced risk of suicide attempts. However, we know very little about the factors associated with either thoughts or acts of selfharm amongst people who gamble. A web-based study of 4125 online gamblers ( $79 \%$ males; mean age 35.5 years), analysed using hierarchical multiple regression, revealed that self-reported nongambling-related self-harm was negatively related to age and marital status, and positively related to problematic alcohol use. Selfreported acts of self-harm both related and unrelated to gambling were associated with drug misuse. Thoughts and acts of gamblingrelated self-harm were associated with problem gambling, gambling involvement and parental problem gambling. All types of self-harm were associated with mood disorder symptoms, unemployment and certain gambling motivations. When tailoring assessment and interventions for individuals at risk for gambling-related deliberate self-harm, it is important to recognize that contributory factors may include some that differ from those for deliberate self-harm in general, and that there is potential value in evaluating gambling involvement and motivations, and history of parental gambling.
\end{abstract}

\section{ARTICLE HISTORY}

Received 12 April 2016 Accepted 14 July 2016

\section{KEYWORDS}

Problem gambling; Internet gambling; mood disorder; substance abuse; suicide

\section{Introduction}

Gambling problems have been linked to suicidal ideation and enhanced risk of suicide attempts (Battersby, Tolchard, Scurrah, \& Thomas, 2006; Brooker, Clara, \& Cox, 2009; Hodgins, Mansley, \& Thygesen, 2006; Manning et al., 2015), likely reflecting the co-occurrence of mood-related disorders and other psychological problems (Wong, Chan, Conwell, Conner, \& Yip, 2010). Hodgins et al. (2006) found that, on average, suicidal ideation began more than 10 years prior to the onset of problematic gambling and was most marked in those with depressive illnesses, and actual suicide attempts were most strongly linked to substance misuse. Similarly, Maccallum and Blaszczynski (2003) reported that suicidal thoughts and acts in a sample of pathological gamblers were more closely related to depression than measures of problem gambling severity. While these data suggest a linkage of problem 
gambling and suicidality largely mediated by co-morbid psychiatric disorder (Hodgins et al., 2006), gambling problems also appear to show significant associations with suicide attempts when the presence of mood and substance misuse disorders is accounted for (Penney, Mazmanian, Jamieson, \& Black, 2012).

In a study of completed suicides, gambling-related cases were less strongly associated with lifetime history of psychiatric diagnoses than non-gambling-related cases (Wong, Cheung, Conner, Conwell, \& Yip, 2010). Similarly, in a sample of in-treatment pathological gamblers with a history of suicide attempts, almost two-thirds cited gambling problems as the principal reason for their most recent attempt (Kausch, 2003). Other studies have also shown features of gambling behaviour to be important, with greater gambling severity (Ledgerwood \& Petry, 2004), gambling as a means of escape (Ledgerwood \& Petry, 2004), longer gambling history and more days per month spent gambling (Ladd \& Petry, 2003) all showing significant associations with suicidality. Collectively, these divergent findings suggest that suicidality in some individuals with gambling problems is explained by cooccurring mood disorders but that in other individuals the relationship with gambling problems is more direct.

Self-harm (i.e. intentional self-injury or self-poisoning) includes acts involving suicidal intent and is strongly associated with suicidal ideation (Gunnell \& Lewis, 2005; Hawton \& van Heeringen, 2009). However, it also encompasses acts with other motivations/reasons (Hawton, Zahl, \& Weatherall, 2003) and is one of the strongest predictors of future selfharm and suicide (Owens, Horrocks, \& House, 2002). While research has explored the links between suicidality and gambling (e.g. Maccallum \& Blaszczynski, 2003), and suicidality is encompassed within self-harm, we know very little about the distal and proximal factors in self-harm in its broader sense amongst gambling populations, and still less about the relationship between self-harm and gambling participation. There is also a dearth of knowledge about the presence of thoughts or ideation about self-harm in this population. In general, suicide ideators exhibit a very similar (but not identical) pattern of risk factors to enactors, with substance abuse (Hodgins et al., 2006) and heavy alcohol use (Gould et al., 1998; Haavisto et al., 2005) being more common amongst those who attempt suicide than amongst those who only think about it. In a study of problem gamblers specifically, both ideators and enactors showed elevated rates of mood disorders compared with controls, and this was more pronounced in the latter (Black et al., 2015). It is possible that a similar pattern of associations will be seen in those who think about self-harm or act on such thoughts.

We surveyed a large sample of online gamblers recruited via gambling websites, with the following two objectives: (i) to investigate the risk factors associated with self-harm in gamblers, and (ii) to determine how these risk factors relate specifically to gambling-related thoughts of self-harm on the one hand, and gambling-related acts of self-harm on the other.

\section{Methods}

Four thousand, one hundred and twenty-five Internet users were recruited via hyperlinks on gambling and gambling-related websites, with the incentive of entry into a prize draw for the chance to win an iPod. An online information sheet and check-box consent form were presented prior to completion of the survey. Respondents provided information about demographic characteristics, self-harm history, online gambling behaviour (frequencies, preferred activities, modes of access) and historical/current gambling problems, and 
completed validated questionnaires for symptoms of mood, alcohol and substance disorders. Further details of the web-based methodology have been described elsewhere (Lloyd et al., 2010a, 2010b).

In order to assess occurrence of self-harm, related and unrelated to gambling, all participants were first asked to respond with a 'yes' or 'no' to the question 'Has there been a time when you thought about harming yourself (in any way) because of problems with your gambling?' Those who responded 'yes' were then asked to answer the question 'Did this ever result in your harming yourself?' All respondents then answered the question 'Have you ever self-harmed (by any means) for other reasons?' These items provided indications of whether participants had a history of non-gambling-related acts of self-harm, gambling-related ideation about self-harm, or gambling-related acts of self-harm. Respondents also completed validated screening questionnaires used to identify the presence of symptoms of psychiatric disorder including the self-report criteria for DSM-IV (Diagnostic and Statistical Manual of Mental Disorders, 4th Edition; American Psychiatric Association, 2000) for problem gambling (scored as positive with a score of 3 or above, as per the British Gambling Prevalence Survey; Wardle, 2007); the Mood Disorders Questionnaire (MDQ) to screen for symptoms of mood elevation and hypomanic experiences (scored as positive with a score of 7 items or more with a self-reported indication that these clustered together in the same period of time and caused moderate to severe problems; Hirschfeld et al., 2000); and the General Health Questionnaire (GHQ-12; Goldberg, 1992) to screen for possible psychological distress. Those scoring above threshold on this also completed the PRIME-MD Patient Health Questionnaire (PHQ-9; Spitzer et al., 1994) to assess DSM-IV items of current depressive symptoms (scored as positive when endorsing five or more out of nine items, including an indication of lowered mood and/or anhedonia; Spitzer, Kroenke, \& Williams, 1999) or panic disorder (scored as positive when all five items were endorsed; Spitzer et al., 1999).

Participants also completed the CAGE alcohol screen (Ewing, 1984) (with a cut-off of 2 used to indicate cases of possible dependence; Hays, Merz, \& Nicholas, 1995) - this fouritem scale was chosen for its brevity, and has adequate psychometric properties, although it performs slightly less well than the longer AUDIT (Meneses-Gaya et al., 2010). They were also asked to indicate which, if any, illicit substances they had used in the last 12 months. Those who had used substances also completed the 10-item Drug Abuse Screening Test (DAST; Skinner, 1982) (positive with a score of 3; Yudko, Lozhkina, \& Fouts, 2007). Finally, all participants provided information about their gambling frequency across a comprehensive list of online and offline activities, and whether their parents gambled, and, if they had, whether the respondent thought that this gambling was problematic.

In order to measure gambling motivations, respondents were asked to rate how often they were motivated to gamble for each of 11 different reasons, which, as reported elsewhere, loaded onto 3 factors broadly defined as the 'coping/mood regulation' motivation factor, the 'enjoyment' motivation factor and the 'monetary' motivation factor (Lloyd et al., 2010a). Each individual was assigned a standardized score for each motivations factor.

\section{Analysis}

We used hierarchical linear regression to test the relationships between history of self-harm (related or unrelated to gambling) on the one hand, and demographic, clinical and gambling-related variables on the other. This analysis treated the three items 'self-harm 
thoughts related to gambling', 'self-harm acts related to gambling' and 'self-harm acts unrelated to gambling' as repeated measures within each participant, in order to account for potential shared variance between the criterion variables (Hoffman \& Rovine, 2007; Woltman, Feldstain, MacKay, \& Rocchi, 2012). The models simultaneously estimated the strength of associations between presence of each of these measures and a single set of regressors (Lloyd et al., 2010a). Some regressors were categorical, and coded in binary format (e.g. gender with 'male' as the reference; employment status with 'employed' as the reference; and the presence of psychological symptoms - i.e. problem gambling, mood elevation, panic disorder, current depressive experiences, drug misuse and alcohol dependence - with 'below threshold for caseness' always the reference. Continuous variables (e.g. age, gambling motivation scores) were represented as regressors in the form of standardized $\mathrm{z}$ scores.

First, gender, marital status, unemployment and age were entered as regressors into a minimal model in order to see how these basic demographic variables were related to the different types of self-harm assessed in the survey. Next, we added problem gambling, mood disturbance, depressive symptoms, panic, alcohol dependence and substance misuse into the model simultaneously to assess the associations involving clinical variables. Finally, a separate model was constructed to look at the effects of gambling-related variables. This included the minimal model (gender, marital status, unemployment and age), to which we simultaneously added gambling volume (defined as the total sum of frequency scores across a comprehensive list of online and offline gambling activities), number of years gambling, and gambling motivation scores (all represented as z scores), along with problem gambling status and parental history of problem gambling (as categorical variables). Throughout, standard $\mathrm{z}$-tests were used to examine the significance of regression coefficients, and statistical significance was taken at the $1 \%$ level $(p<.01)$. The larger the $\mathrm{z}$-value (the mean of the regression coefficients divided by their standard error), the stronger the observed relationship between the motivation factor score and regressor. Analyses were conducted with SPSS 15 and MLWin 2.02 (http://www.cmm.bristol.ac.uk/MLwiN/index.shtml).

\section{Ethical approval}

The survey was approved by a United Kingdom National Health Service Research Ethics Committee (OXREC C; 06/Q1606/151). After the presentation of an information page detailing the study, informed consent was obtained electronically, within the web survey.

\section{Results}

Demographic and clinical characteristics of the participants are presented in Table 1 and are broadly typical of those reported in previous samples of Internet gamblers in European and North American contexts (Griffiths, Wardle, Orford, Sproston, \& Erens, 2008; McBride \& Derevensky, 2009; Petry \& Kiluk, 2002; Petry, Litt, Kadden, \& Ledgerwood, 2007; Wood \& Williams, 2007). Of 4125 respondents, $7.3 \%$ indicated that they had contemplated harming themselves because of their gambling problems. Of the contemplators, $28.0 \%$ (2.0\% of the total sample) reported that they had actually self-harmed because of gambling problems. While only those who had contemplated self-harm related to gambling problems were asked whether this led to them going on to actually self-harm, it was assumed that those who had never contemplated self-harm had not gone on to self-harm, so a 'no' response 
Table 1. Demographic and clinical characteristics of the sample.

\begin{tabular}{|c|c|}
\hline Characteristic & Value \\
\hline \multicolumn{2}{|l|}{ Demographic } \\
\hline$M$ age in years $(S D)$ & $35.5(11.8)$ \\
\hline No. of female participants (\%) & $859(20.9)$ \\
\hline No. of UK residents (\%) & $2836(68.8)$ \\
\hline \multicolumn{2}{|l|}{ Marital status, no. (\%) } \\
\hline Single & $1704(41.4)$ \\
\hline Married or living with partner & $2170(52.8)$ \\
\hline Divorced, separated or widowed & $239(5.8)$ \\
\hline \multicolumn{2}{|l|}{ Educational background, no. (\%): } \\
\hline Degree level or above & $1724(41.8)$ \\
\hline College/vocational training & $1488(36.0)$ \\
\hline Secondary and/or primary education & $913(22.2)$ \\
\hline \multicolumn{2}{|l|}{ Employment status, no. (\%) } \\
\hline Full-time employed & $2303(55.8)$ \\
\hline Part-time employed & $254(6.2)$ \\
\hline Self-employed & $469(11.4)$ \\
\hline Unemployed & $273(6.6)$ \\
\hline Retired & $193(4.7)$ \\
\hline Taking care of the house & $196(4.8)$ \\
\hline Student (undergraduate/postgraduate) & $437(10.6)$ \\
\hline \multicolumn{2}{|l|}{ Clinical } \\
\hline No. (\%) reporting thoughts about self-harm because of gambling & $300(7.3)$ \\
\hline No. (\%) reporting acts of self-harm because of gambling & $84(2.0)$ \\
\hline No. (\%) reporting acts of self-harm unrelated to gambling & $448(10.9)$ \\
\hline No. (\%) problem gambling cases (above threshold on DSM-IV) & $841(20.5)$ \\
\hline No. (\%) cases of lowered mood (above threshold on PRIME PHQ-9) & $343(8.3)$ \\
\hline No. (\%) cases of mood elevation (above threshold on MDQ) & $275(6.7)$ \\
\hline No. (\%) cases of panic disorder (above threshold on PRIME) & $133(3.2)$ \\
\hline No. (\%) substance misuse cases (above threshold on DAST) & $332(8.1)$ \\
\hline No. (\%) cases problematic alcohol use (above threshold on CAGE) & $1242(30.2)$ \\
\hline
\end{tabular}

Note: PRIME PHQ-9 = PRIME Patient Health Questionnaire, 9-item; MDQ = Mood Disorders Questionnaire; DAST = Drug Abuse Screening Test; CAGE = CAGE alcohol screen.

was imputed for those who did not receive the question. Overall, 448 respondents $(10.9 \%$ of the overall sample) indicated a history of having harmed themselves in the past for other reasons not related to gambling.

\section{Gambling and non-gambling-related self-harm and demographics}

Table 2 shows that non-gambling-related acts of self-harm were reported more frequently by females $(z=7.25, p<.0001)$ and respondents who were unemployed $(z=6.63, p<.0001)$, and less frequently by older people $(z=-4.00, p<.0001)$ and those who were married or had a partner $(z=-3.30, p<.001)$. However, females were less likely to have considered self-harm

Table 2. Multivariate hierarchical regression; basic model: associations between thoughts and acts of self-harm related and unrelated to gambling, and demographic characteristics.

\begin{tabular}{|c|c|c|c|c|c|c|c|c|c|c|c|c|}
\hline & \multicolumn{4}{|c|}{$\begin{array}{l}\text { Thoughts of self-harm: } \\
\text { related to gambling }\end{array}$} & \multicolumn{4}{|c|}{$\begin{array}{l}\text { Acts of self-harm: related to } \\
\text { gambling }\end{array}$} & \multicolumn{4}{|c|}{$\begin{array}{c}\text { Acts of self-harm: unrelated } \\
\text { to gambling }\end{array}$} \\
\hline & Mean $\beta$ & SE & $Z$ & $p$ & Mean $\beta$ & SE & $Z$ & $p$ & Mean $\beta$ & SE & $Z$ & $p$ \\
\hline Female & -0.043 & 0.010 & -4.30 & *** & -0.004 & 0.005 & -0.80 & .21 & 0.087 & 0.012 & 7.25 & **** \\
\hline Age $(z)$ & -0.003 & 0.004 & -0.75 & .23 & -0.001 & 0.002 & -0.50 & .31 & -0.020 & 0.005 & -4.00 & **** \\
\hline Married/live with partner & -0.015 & 0.009 & -1.67 & .05 & -0.002 & 0.005 & -0.40 & .34 & -0.033 & 0.010 & -3.30 & ** \\
\hline Unemployed & 0.065 & 0.016 & 4.06 & *** & 0.021 & 0.009 & 2.33 & & 0.126 & 0.019 & 6.63 & *** \\
\hline
\end{tabular}

${ }^{*} Z>2.3, p<.01 ;{ }^{* *} Z>3.09 ; p<.001 ;{ }^{* * *} Z>3.72 ; p<.0001$. 
because of gambling-related problems than males $(z=-4.30, p<.0001)$. Unemployment was the only demographic characteristic that was significantly related to having actually self-harmed because of gambling-related problems $(z=2.33, p<.01)$, and it was also significantly associated with having thought about self-harm because of gambling-related problems $(z=4.06, p<.0001)$.

\section{Self-harm and psychological symptoms}

Table 3 shows the basic model with 'caseness' for each of the psychological disorders added simultaneously. Gambling-related thoughts of self-harm were significantly associated with problem gambling $(z=18.70, p<.0001)$, previous problematic hypomanic experiences (as scored on the MDQ; $z=9.81, p<.0001)$, and current depression $(z=7.60, p<.0001)$ and panic 'caseness' (as scored on the PRIME; $z=4.74, p<.0001$ ), but not with drinking problems (as scored with the CAGE; $z=-0.50, \mathrm{p}=.31$ ) or drug use disorders (as scored by the DAST; $z=0.50, \mathrm{p}=0.31$ ). Gambling-related acts of self-harm showed a very similar pattern, again being associated with problem gambling $(z=7.50, p<0001)$, problematic hypomanic experiences $(z=5.00, p<$. 0001), and 'caseness' for depression $(z=4.44$, $p<.0001)$ and panic $(z=3.69, p<.001)$, and showing no significant association with drinking problems $(z=1.20, \mathrm{p}=0.11)$. They were, however, associated with drug use disorders $(z=3.36, p<.001)$. Non-gambling-related acts of self-harm were not associated with problem gambling, but they were associated with all the other psychiatric disorder caseness variables; that is, problematic hypomanic experiences $(z=4.85, p<.0001)$, caseness for depression $(z=4.58, p<.0001)$ and panic $(z=6.24, p<.0001)$, drinking problems $(z=5.60$, $p<.0001)$ and drug use disorders $(z=6.06, p<.0001)$.

\section{Gambling characteristics}

Table 4 shows the associations between gambling and non-gambling-related self-harm thoughts and acts and the gambling behaviours and motivations. Having thought about

Table 3. Multivariate hierarchical regression; disorders model: thoughts \& acts of self-harm related and unrelated to gambling in basic model with psychiatric disorder caseness variables.

\begin{tabular}{|c|c|c|c|c|c|c|c|c|c|c|c|c|}
\hline & \multicolumn{4}{|c|}{$\begin{array}{l}\text { Thoughts of self-harm: } \\
\text { related to gambling }\end{array}$} & \multicolumn{4}{|c|}{$\begin{array}{l}\text { Acts of self-harm: related to } \\
\text { gambling }\end{array}$} & \multicolumn{4}{|c|}{$\begin{array}{c}\text { Acts of self-harm: unrelated } \\
\text { to gambling }\end{array}$} \\
\hline & Mean $\beta$ & SE & $Z$ & $p$ & Mean $\beta$ & SE & $Z$ & $p$ & Mean $\beta$ & SE & $Z$ & $p$ \\
\hline Gender (female) & -0.033 & 0.009 & -3.67 & *** & -0.001 & 0.005 & -0.20 & .42 & 0.088 & 0.012 & 7.33 & **** \\
\hline Age (z-score) & 0.006 & 0.004 & 1.50 & .07 & 0.002 & 0.002 & 1.00 & .16 & -0.015 & 0.005 & -3.00 & $*$ \\
\hline $\begin{array}{l}\text { Married/living with } \\
\text { partner }\end{array}$ & -0.005 & 0.008 & -0.63 & .26 & 0.001 & 0.005 & 0.20 & .42 & -0.027 & 0.010 & -2.70 & ${ }^{*}$ \\
\hline Unemployed & 0.003 & 0.015 & 0.20 & .42 & -0.001 & 0.009 & -0.11 & .46 & -0.073 & 0.019 & -3.84 & $* *$ \\
\hline Problem gambling & 0.187 & 0.010 & 18.70 & $* * *$ & 0.045 & 0.006 & 7.50 & & 0.019 & 0.012 & 1.58 & .06 \\
\hline $\begin{array}{l}\text { Mood elevation } \\
\text { (MDQ) caseness }\end{array}$ & 0.157 & 0.016 & 9.81 & $* * *$ & 0.045 & 0.009 & 5.00 & $* * *$ & 0.097 & 0.020 & 4.85 & \\
\hline Panic caseness & 0.109 & 0.023 & 4.74 & $* * *$ & 0.048 & 0.01 & 3.69 & $* *$ & 0.181 & 0.029 & 6.24 & $* * *$ \\
\hline $\begin{array}{l}\text { Depressed mood } \\
\text { (PRIME) caseness }\end{array}$ & 0.114 & 0.015 & 7.60 & $* * *$ & 0.040 & 0.009 & 4.44 & $* * *$ & 0.087 & 0.019 & 4.58 & $* * *$ \\
\hline $\begin{array}{l}\text { Drug misuse (DAST) } \\
\text { caseness }\end{array}$ & 0.007 & 0.014 & 0.50 & .31 & 0.027 & 0.008 & 3.36 & ${ }^{* *}$ & 0.109 & 0.018 & 6.06 & $* * *$ \\
\hline $\begin{array}{l}\text { Alcohol dependence } \\
\text { (CAGE) caseness }\end{array}$ & -0.004 & 0.008 & -0.50 & .31 & 0.006 & 0.005 & 1.20 & .11 & 0.056 & 0.010 & 5.60 & $* * *$ \\
\hline
\end{tabular}

${ }^{*} Z>2.3, p<.01 ;{ }^{* *} Z>3.09 ; p<.001 ;{ }^{* * *} Z>3.72 ; p<.0001$. 


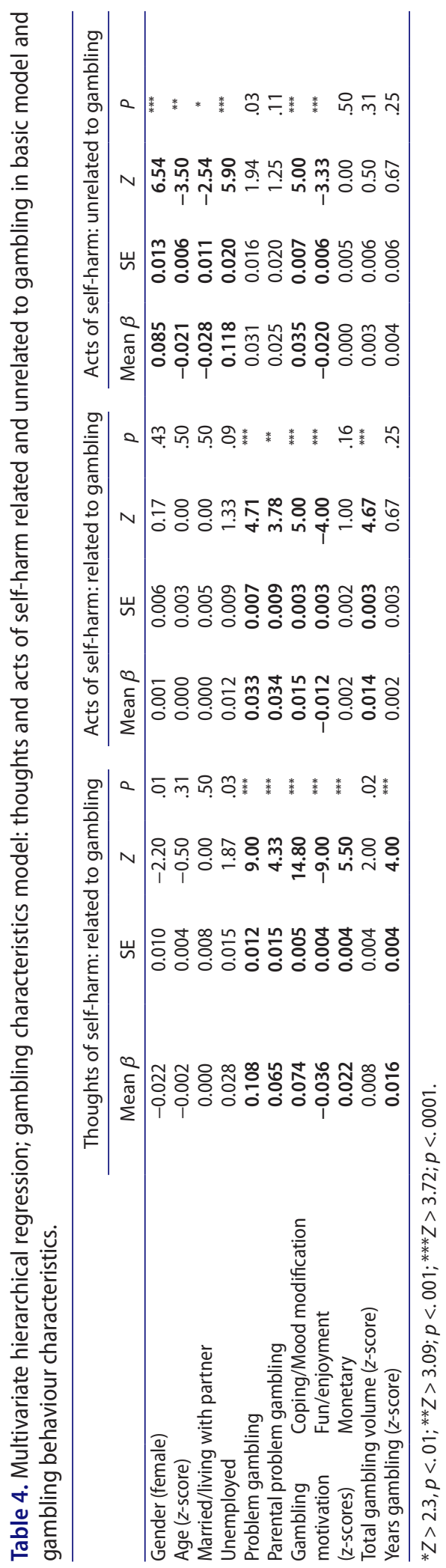


harming oneself because of gambling-related problems was associated with problem gambling $(z=9.00, p<.0001)$, parental problem gambling $(z=4.33, p<.0001)$, number of years gambling $(z=4.00, p<.0001)$, gambling for mood modification $(z=14.80, p<.0001)$ and for monetary motives $(z=5.50, p<.0001)$ but negatively associated with gambling for enjoyment motives $(z=-9.00, p<.0001)$.

Having actually harmed oneself because of problems related to gambling showed broadly the same set of associations as having thought about it. That is, gambling-related selfharm was associated with problem gambling $(z=4.71, p<.0001)$ and reports of parental problem gambling $(z=3.78, p<.001)$ and with gambling for mood modification $(z=5.00$, $p<.0001)$, but negatively associated with gambling for enjoyment $(z=-4.00, p<.0001)$. It was associated with gambling volume $(z=4.67, p<.0001)$ but not with number of years gambling $(z=0.67, \mathrm{p}=.25)$, nor with gambling for monetary motives $(z=1.00, \mathrm{p}=0.16)$.

Having harmed oneself for reasons unrelated to gambling was also significantly associated with gambling for mood modification $(z=5.00, p<.0001)$, and was inversely associated with gambling for enjoyment $(z=-3.33, p<.0001)$. Non-gambling related self-harm did not show reliable relationships with any of the other gambling-related variables (i.e. problem gambling, parental problem gambling, gambling for monetary reasons, years gambling or gambling volume; all p-values $>.05$ ).

\section{Discussion}

In an online sample of over 4000 respondents we identified characteristic factors strongly associated with non-gambling-related self-harm (female gender, age, unmarried/unpartnered marital status and problematic alcohol and substance use), others that were strongly associated with gambling-related thoughts and/or acts of self-harm (problem gambling, parental problem gambling and gambling involvement) and some that were related to all types of self-harm acts, both related and unrelated to gambling (mood disorders, unemployment and certain types of gambling motivation). While links between suicide attempts and gambling problems have been reported previously (e.g. Battersby et al., 2006; Hodgins et al., 2006; Maccallum \& Blaszczynski, 2003; Manning et al., 2015), to our knowledge this is the first study to investigate the ways that thoughts and acts of self-harm more broadly (i.e. not specifically constrained to those with suicidal intent) relate to gambling problems alongside other health experiences. The results can help inform assessment and treatment of gamblers who may be at risk of self-harm.

\section{Self-harm and demographic characteristics of gamblers}

Consistent with findings of research on self-harm in general, non-gambling-related acts of self-harm were more frequent in females, younger individuals (Hawton, 2000) and those who were unemployed (Young, Van Beinum, Sweeting, \& West, 2007), and less frequent in those who were married/partnered (Klonsky, 2011). Gambling-related thoughts of self-harm were also more frequent in those who were unemployed, but in contrast to non-gambling related self-harm they were not associated with marital status and were most frequent in males. Gambling-related acts of self-harm were associated with unemployment, but had no relationship to gender or marital status. Age was not a significant predictor of either thoughts or acts of gambling-related self-harm. 
That males were more likely than females to report thoughts of gambling-related selfharm contrasts with findings that they are less likely to report acts of non-gambling-related self-harm, both in our sample and in other studies (Bischof et al., 2015; Evans, Hawton, \& Rodham, 2005), and was not predicted a priori. This relationship remained statistically significant even when problem gambling was included as a regressor, suggesting that it did not reflect a bias towards more severe gambling problems in males. Finally, the observation that male gender was not significantly associated with acts of gambling-related self-harm could indicate that gambling-related self-harm ideation is more common in male gamblers or that our statistical power to detect relationships with other variables is limited by the relative infrequency of gambling-related self-harm acts. In any case, the usual pattern of higher risk of self-harm amongst females (Hawton et al., 2003) may be absent or even reversed in gambling-related self-harm. This may be relevant when assessing or treating problem gamblers.

We also found that neither gambling-related thoughts of self-harm nor gambling-related acts of self-harm were more commonly reported in younger compared to older respondents, possibly indicating that, in contrast to non-gambling-related self-harm (Klonsky, 2011), the risk of gambling-related self-harm does not decline with age. However, the lifetime time frame used in the self-harm questions, and the fact that duration of problem gambling was not included in the model, limits the conclusions that can be made about age effects. This relationship merits further study for its potential clinical significance, particularly given that self-harm in older age is associated with higher suicidal intent (Voshaar et al., 2011) and greater likelihood of completed suicide (Hawton et al., 2003; Murphy et al., 2012). Also, gambling participation is increasing in older sectors of the population (McNeilly \& Burke, 2001; Pilver, Libby, Hoff, \& Potenza, 2013; Tse, Hong, Wang, \& Cunningham-Williams, 2012).

\section{Mood and substance disorders and self-harm}

Gambling-related thoughts of self-harm were associated with mood symptoms (as indicated by positive 'caseness' for depression, panic and hypomania). Both gambling-related and non-gambling-related acts of self-harm were associated with each of these symptom-sets and, in addition, with drug misuse. The links with mood disorders are consistent with the literature on self-harm in general, where co-occurrence of psychiatric disorders is common (Haw, Hawton, Houston, \& Townsend, 2001). Our findings demonstrate that these moodrelated factors also operate in self-harm linked to gambling or the experience of gambling problems. Interestingly, alcohol dependence was not associated with either thoughts or acts of gambling-related self-harm, in contrast to its links with non-gambling-related self-harm. This suggests that not all the factors associated with self-harm in general appear to apply in gambling-specific cases of self-harm.

Our study is unusual in including a measure of hypomanic experience. The bipolar spectrum extends to $4-5 \%$ of the population (Merikangas et al., 2007). Bipolar diagnoses are associated with an increased risk of anxiety disorder (Merikangas, Jin, He, et al., 2011), substance misuse (Levin \& Hennessy, 2004), self-harm (Hawton, Sutton, Haw, Sinclair, \& Harriss, 2005) and of gambling itself (McIntyre et al., 2007). Inquiry about hypomanic experience should accordingly be an important part of clinical assessment and may shape treatment options. 


\section{Self-harm and gambling-related behaviours}

Gambling-related thoughts of self-harm were significantly and positively associated with self-reported problem gambling, reported parental problem gambling, and number of years gambling. In addition, gambling-related self-harm thoughts were positively linked to both 'coping' and 'monetary' gambling motivations, but were inversely associated with the 'enjoyment' motivations. Gambling-related acts of self-harm showed similar links though there were no significant associations with 'monetary' motivations or with years gambling, but a significant association with current gambling volume. This latter effect may suggest that current level of involvement in gambling, rather than the duration of individuals' gambling history, is the more informative variable for judging risk of actual self-harm.

Non-gambling-related acts of self-harm were also significantly and positively associated with 'coping' gambling motivation score and significantly and negatively associated with 'enjoyment' gambling motivation score, but showed no significant association with other gambling-related variables (i.e. problem gambling, gambling involvement and years gambling, and suspected parental problem gambling). This indicates that, while there are differences in the associations with gambling-related vs. non-gambling-related self-harm, there are also some common factors. The finding that gambling to cope is associated with non-gambling-related acts of self-harm is intriguing. Coping with adverse experiences has been cited as one of the top three motivators for 'non-suicidal self-injury' (Wilcox et al., 2012), and self-harm has been shown to be associated with maladaptive coping styles (Christian \& McCabe, 2011; Evans, Hawton, Rodham, Psychol, \& Deeks, 2005). In the current study, 'gambling to cope', as a motivating factor, may constitute an indirect measure of maladaptive coping, or it may simply be associated with the presence of lowered mood or depressive symptoms, that are in turn associated with gambling to modify mood and negative emotional states (Blaszczynski \& Nower, 2002; Lloyd et al., 2010a). Regardless of the precise mechanism, the observation that these motivations were significantly linked to self-harm, even when problem gambling was included in the statistical model, highlights their potential as a new source of information when examining emotional risk factors for self-harm in gamblers.

\section{Limitations}

Before considering the implication of our findings, we acknowledge some limitations. First, our study is subject to the inherent limitations of a web-based survey methodology (i.e. lack of control over multiple responses, and lack of clinical interview data available to determine whether respondents represent true clinical cases of disorders) and to those of a self-selected sample (e.g. potential bias in type of respondent, limited generalizability, and inability to indicate general prevalence). In particular, it is likely that the online recruitment method resulted in an over-representation of online gamblers. While the majority of participants also engaged in offline gambling, there are differences between 'online', 'offline' and 'mixedmode' gamblers in terms of type and number of activities engaged in, and tendency to experience gambling problems (Gainsbury, Russell, Blaszczynski, \& Hing, 2015). Similarly, while the sample contained participants from a wide variety of geographical locations, over two-thirds were UK residents, and this may limit the generalizability of findings, given that gambling ecology varies considerably between countries (Abbott et al., 2013). It is also 
worth noting that we did not ask whether respondents who reported problematic gambling were seeking treatment. Although co-morbid mood disorders, including depression, are prevalent amongst treatment-seeking problem gamblers (Dowling et al., 2015), suggesting that self-harm amongst this sample is likely to be a pertinent concern, the extent to which the predictors of self-harm identified in the current study apply specifically to the treatment-seeking gamblers whom clinicians are most likely to encounter in clinical practice is difficult to estimate. Thus, caution should be exercised in generalizing from this study to the broader population of gamblers as a whole, and future research could explore whether similar predictors of gambling-related self-harm apply within samples of exclusively offline gamblers, amongst gamblers from different geographical locations and amongst samples of treatment-seeking problem gamblers.

Because the study was cross-sectional we are unable to draw conclusions about direction of causality; further longitudinal research is needed in order to determine whether the associations observed indicate predictive risk factors for future self-harm.

Self-harm was assessed via three purpose-written items, which allowed for the creation of questions asking specifically about gambling-related self-harm, and minimized response burden (this was important as the current study formed part of a larger survey with multiple scales included, in addition to those described here; Lloyd et al., 2010). However, the lack of an explicit definition of deliberate self-harm (or use of a pre-validated measure) raises the possibility that some respondents may have classified any harmful behaviours, such as poor lifestyle or substance misuse, as 'self-harm'. However, if this were the case, we might expect considerable elevation in reporting rates, whereas approximately $11 \%$ of the sample reported self-harming for reasons unrelated to gambling, which is consistent with estimated prevalence rates of self-harm in young people in the general population of 7-14\% (Evans et al., 2005). In addition, the order of the questions (enquiring whether the respondents had thought about harming themselves, before asking whether they had gone on to do so) was intended to prime respondents to consider specific, premeditated acts of deliberate self-harm, rather than retrospectively assess whether gambling caused them to behave in an unhealthy or risky manner. Nonetheless, the inclusion of a pre-validated measure such as the Self-Harm Inventory (Sansone \& Sansone, 2010) could have increased confidence in the applicability of the current study's findings to clinical measures of self-harm, and should be considered in future studies.

A key strength lies in the sample size that allowed the use of hierarchical regression models against validated screening assessments for psychological disorders. Furthermore, web-based studies can provide valid and practical methods of obtaining data in hardto-access populations (e.g. Wood \& Griffiths 2007), yielding comparable results to postal surveys, even on sensitive topics (McCabe, 2004).

\section{Summary and clinical implications}

We have identified a number of features strongly associated with self-harm in online gamblers, and those specifically related to problem gambling. The findings highlight the potential importance of clinicians asking about gambling as a possible reason for self-harm in general, and of assessing risk of self-harm or suicide in problem gamblers. Indeed, we suggest that such enquiry should be routinely included in clinical assessment in these situations, including in older as well as younger people. Treatment for gambling-related problems (Seguin et al., 2010) 
may be an essential component of successful intervention in individuals at risk. Longitudinal investigations of at-risk gamblers could help further elaborate the associations with thoughts and acts of self-harm, and hence also increase our understanding of the relationship of gambling to suicide.

\section{Conflicts of interest}

\section{Competing interests}

The authors reported no biomedical financial interests nor potential conflicts of interests of relevance to this study. Keith Hawton, Guy Goodwin and John Geddes are National Institute for Health Research (NIHR) senior investigators. The views expressed are those of the authors and not necessarily those of the National Health Service (NHS), the NIHR or the Department of Health.

\section{Constraints on publishing}

The funding agencies had no involvement in the research design, methodology, conduct, analysis or write-up. No constraints on publishing were reported by the authors.

\section{Funding sources}

This work was supported by the Responsibility in Gambling Trust and the Economic and Social Research Council (ESRC), under grant number 164-25-0008.

\section{Notes on contributors}

Joanne Lloyd is a psychology lecturer at the University of Staffordshire, and researches online gambling, with particular interests in the differences and similarities between online and offline gambling; gambling motivations and their relationship with problem VS. non-problem gambling; and the co-morbidity of mood-related and gambling disorders. She is involved in both quantitative and qualitative research.

Keith Hawton is professor of psychiatry and director of the Centre for Suicide Research at Oxford University Department of Psychiatry. He is also a National Institute for Health Research senior investigator and fellow of the Academy of Medical Sciences. His research group conducts investigations concerning the causes, treatment, prevention and outcome of suicidal behaviour. He has received the following awards: Stengel Research Award from the International Association for Suicide Prevention, Dublin Career Research Award from the American Association of Suicidology, Research Award of the American Foundation for Suicide Prevention and the Morselli Medal from the International Association of Suicide Research.

William H. Dutton is the Quello professor of media and information policy in the College of Communication Arts and Sciences at Michigan State University, where he is director of the Quello Center. He was the first professor of Internet studies at the University of Oxford, where he was founding director of the Oxford Internet Institute.

John R. Geddes is professor of epidemiological psychiatry, director of the NIHR Oxford Cognitive Health Clinical Research Facility, director of Oxford Cognitive Health and Neuroscience Clinical Trial Unit and head of the Department of Psychiatry at the University of Oxford. His research focuses on the development and evaluation of treatments for people with bipolar and other mental disorders, and has generated high quality evidence to guide clinical practice, which has been influential 
in international clinical practice guidelines. His research group's strategy increasingly combines the power of large-scale epidemiological methods with the precision of neurobiological investigation.

Guy M. Goodwin, DPhil, FMedSci is currently senior research fellow and was until 2014 W. A. Handley professor of psychiatry at the University of Oxford, UK. His research interests are in the treatment of bipolar disorder and the application of neuroscience in understanding the neurobiology of mood disorders, with a focus on developing new treatments. He works with industry in developing translational models of psychotropic drug action in man. He is president of the European College of Neuropsychopharmacology (ECNP; 2013-2016) and a senior investigator in the faculty of UK National Institute for Health Research (NIHR; 2011-2017).

Robert D. Rogers is a member of the Clinical, Health, and Behavioural Psychology research group at the University of Bangor, and an expert in the fields of cognitive control and decision-making. He conducts research into the neural and neurochemical substrates of emotional (and irrational) decision-making in non-social and social contexts, and recently extended this work into the neural mechanisms underlying psychological disorders such as problem gambling and bipolar disorder. This includes studying the role of serotonin and dopamine in shifts between risk-seeking and risk-averse behaviour, and the neural substrates of cognitive biases in gambling behaviour, such as loss-chasing.

\section{References}

Abbott, M., Binde, P., Hodgins, D., Korn, D., Pereira, A., Volberg, R., \& Williams, R. (2013). Conceptual framework of harmful gambling: An international collaboration. Guelph: Ontario Problem Gambling Research Centre (OPGRC).

American Psychiatric Association (4th ed.). (2000). Diagnostic and statistical manual of Mental Disorders. Washington DC: American Psychiatric Publishing.

Battersby, M., Tolchard, B., Scurrah, M., \& Thomas, L. (2006). Suicide ideation and behaviour in people with pathological gambling attending a treatment service. International Journal of Mental Health and Addiction, 4, 233-246. doi:10.1007/s11469-006-9022-z

Bischof, A., Meyer, C., Bischof, G., John, U., Wurst, F. M., Thon, N., \& Rumpf, H. J. (2015). Suicidal events among pathological gamblers: The role of comorbidity of axis I and axis II disorders. Psychiatry Research, 225, 413-419.

Black, D. W., Coryell, W., Crowe, R., McCormick, B., Shaw, M., \& Allen, J. (2015). Suicide ideations, suicide attempts, and completed suicide in persons with pathological gambling and their firstdegree relatives. Suicide and Life Threatening Behavior, 45, 700-709.

Blaszczynski, A., \& Nower, L. (2002). A pathways model of problem and pathological gambling. Addiction, 97, 487-499.

Brooker, I. S., Clara, I. P., \& Cox, B. J. (2009). The canadian problem gambling index: Factor structure and associations with psychopathology in a nationally representative sample. Canadian Journal of Behavioural Science, 41, 109-114. doi:10.1037/A0014841

Christian, A. S., \& McCabe, K. M. (2011). Coping style as a mediator of the relationship between depressive symptoms and deliberate self-harm. Crisis, 32, 272-279. doi:10.1027/0227-5910/a000083

Dowling, N. A., Cowlishaw, S., Jackson, A. C., Merkouris, S. S., Francis, K. L., \& Christensen, D. R. (2015). Prevalence of psychiatric co-morbidity in treatment-seeking problem gamblers: A systematic review and meta-analysis. Australian and New Zealand Journal of Psychiatry, 49, 519-539.

Evans, E., Hawton, K., \& Rodham, K. (2005). In what ways are adolescents who engage in self-harm or experience thoughts of self-harm different in terms of help-seeking, communication and coping strategies? Journal of Adolescence, 28, 573-587. doi:10.1016/j.adolescence.2004.11.001

Evans, E., Hawton, K., Rodham, K., Psychol, C., \& Deeks, J. (2005). The prevalence of suicidal phenomena in adolescents: A systematic review of population-based studies. Suicide and Life Threatening Behavior, 35, 239-250. doi:10.1521/suli.2005.35.3.239

Ewing, J. A. (1984). Detecting alcoholism: The CAGE questionaire. JAMA, 252, 1905-1907. 
Gainsbury, S. M., Russell, A., Blaszczynski, A., \& Hing, N. (2015). The interaction between gambling activities and modes of access: A comparison of Internet-only, land-based only, and mixed-mode gamblers. Addictive Behaviors, 41, 34-40.

Goldberg, D. (1992). General Health Questionnaire (GHQ-12). Windsor, UK: NFER-Nelson.

Gould, M. S., King, R., Greenwald, S., Fisher, P., Schwab-Stone, M., Kramer, R., \& Shaffer, D. (1998). Psychopathology associated with suicidal ideation and attempts among children and adolescents. Journal of the American Academy of Child \& Adolescent Psychiatry, 37, 915-923. doi:10.1097/00004583-199809000-00011

Griffiths, M., Wardle, H., Orford, J., Sproston, K., \& Erens, B. (2008). Sociodemographic correlates of Internet gambling: Findings from the 2007 British gambling prevalence survey. Cyberpsychology and Behavior, 12, 199-202.

Gunnell, D., \& Lewis, G. (2005). Studying suicide from the life course perspective: Implications for prevention. British Journal of Psychiatry, 187, 206-208. doi:10.1192/bjp.187.3.206

Haavisto, A., Sourander, A., Multimaki, P., Parkkola, K., Santalahti, P., Helenius, H., \& Almqvist, F. (2005). Factors associated with ideation and acts of deliberate self-harm among 18-year-old boys. A prospective 10-year follow-up study. Social Psychiatry and Psychiatric Epidemiology, 40, 912-921. doi:10.1007/s00127-005-0966-2

Haw, C., Hawton, K., Houston, K., \& Townsend, E. (2001). Psychiatric and personality disorders in deliberate self-harm patients. British Journal of Psychiatry, 178, 48-54.

Hawton, K. (2000). Sex and suicide. Gender differences in suicidal behaviour. British Journal of Psychiatry, 177, 484-485.

Hawton, K., Harriss, L., Hall, S., Simkin, S., Bale, E., \& Bond, A. (2003). Deliberate self-harm in Oxford, 1990-2000: A time of change in patient characteristics. Psychological Medicine, 33, 987995. doi:10.1017/S0033291703007943

Hawton, K., Sutton, L., Haw, C., Sinclair, J., \& Harriss, L. (2005). Suicide and attempted suicide in bipolar disorder: A systematic review of risk factors. Journal of Clinical Psychiatry, 66, 693-704.

Hawton, K., \& van Heeringen, K. (2009). Suicide. Lancet, 373, 1372-1381. doi:10.1016/S01406736(09)60372-X

Hawton, K., Zahl, D., \& Weatherall, R. (2003). Suicide following deliberate self-harm: Long-term follow-up of patients who presented to a general hospital. British Journal of Psychiatry, 182, 537-542.

Hays, R. D., Merz, J. F., \& Nicholas, R. (1995). Response burden, reliability, and validity of the CAGE, Short MAST, and AUDIT alcohol screening measures. Behavior Research Methods, Instruments, \& Computers, 27, 277-280.

Hirschfeld, R. M., Williams, J. B., Spitzer, R. L., Calabrese, J. R., Flynn, L., Keck, P. E., Jr, Zajecka, J. (2000). Development and validation of a screening instrument for Bipolar Spectrum Disorder: The Mood Disorder questionnaire. American Journal of Psychiatry, 157, 1873-1875.

Hodgins, D. C., Mansley, C., \& Thygesen, K. (2006). Risk factors for suicide ideation and attempts among pathological gamblers. American Journal of Addiction, 15, 303-310. doi:10.1080/10550490600754366

Hoffman, L., \& Rovine, M. J. (2007). Multilevel models for the experimental psychologist: Foundations and illustrative examples. Behavior Research Methods, 39, 101-117.

Kausch, O. (2003). Suicide attempts among veterans seeking treatment for pathological gambling. Journal of Clinical Psychiatry, 64, 1031-1038.

Klonsky, E. D. (2011). Non-suicidal self-injury in United States adults: Prevalence, sociodemographics, topography and functions. Psychological Medicine, 41, 1981-1986. doi:10.1017/S0033291710002497

Ladd, G. T., \& Petry, N. M. (2003). A comparison of pathological gamblers with and without substance abuse treatment histories. Experimental and Clinical Psychopharmacology, 11, 202-209. doi:10.1037/1064-1297.11.3.202

Ledgerwood, D. M., \& Petry, N. M. (2004). Gambling and suicidality in treatment-seeking pathological gamblers. Journal of Nervous and Mental Disease, 192, 711-714. doi: 00005053-200410000-00012 [pii].

Levin, F. R., \& Hennessy, G. (2004). Bipolar Disorder and substance abuse. Biological Psychiatry, 56, 738-748. doi:10.1016/j.biopsych.2004.05.008 
Lloyd, J., Doll, H., Hawton, K., Dutton, W. H., Geddes, J. R., Goodwin, G. M., \& Rogers, R. D. (2010). How psychological symptoms relate to different motivations for gambling: an online study of internet gamblers. Biological Psychiatry, 68, 733-740. doi:10.1016/j.biopsych.2010.03.038.

Lloyd, J., Doll, H., Hawton, K., Dutton, W. H., Geddes, J. R., Goodwin, G. M., \& Rogers, R. D. (2010b). Internet gamblers: A latent class analysis of their behaviours and health experiences. Journal of Gambling Studies, 26, 387-399. doi:10.1007/s10899-010-9188-y

Maccallum, F., \& Blaszczynski, A. (2003). Pathological gambling and suicidality: An analysis of severity and lethality. Suicide and Life Threatening Behavior, 33, 88-98.

Manning, V., Koh, P. K., Yang, Y., Ng, A., Guo, S., Kandasami, G., \& Wong, K. E. (2015). Suicidal ideation and lifetime attempts in substance and gambling disorders. Psychiatry Research, 225, 706-709.

McBride, J., \& Derevensky, J. L. (2009). Internet gambling behavior in a sample of online gamblers. International Journal of Mental Health and Addiction, 7, 149-167.

McCabe, S. E. (2004). Comparison of web and mail surveys in collecting illicit drug use data: A randomized experiment. Journal of Drug Education, 34, 61-72.

McIntyre, R. S., McElroy, S. L., Konarski, J. Z., Soczynska, J. K., Wilkins, K., \& Kennedy, S. H. (2007). Problem gambling in bipolar disorder: Results from the Canadian Community Health Survey. Journal of Affective Disorders, 102, 27-34. doi:10.1016/j.jad.2006.12.005

McNeilly, D. P., \& Burke, W. J. (2001). Gambling as a social activity of older adults. International Journal of Aging and Human Development, 52, 19-28.

Meneses-Gaya, C., Zuardi, A. W., Loureiro, S. R., Hallak, J. E., Trzesniak, C., de Azevedo Marques, J. M., ... \& Crippa, J. A. (2010). Is the full version of the AUDIT really necessary? Study of the validity and internal construct of its abbreviated versions. Alcoholism: Clinical and Experimental Research, 34, 1417-1424.

Merikangas, K. R., Akiskal, H. S., Angst, J., Greenberg, P. E., Hirschfeld, R. M., Petukhova, M., \& Kessler, R. C. (2007). Lifetime and 12-month prevalence of bipolar spectrum disorder in the National Comorbidity Survey replication. Archives of General Psychiatry, 64, 543-552.

Merikangas, K. R., Jin, R., He, J., et al. (2011). Prevalence and correlates of Bipolar Spectrum Disorder in the world mental health survey initiative. Archives of General Psychiatry, 68, 241-251. doi:10.1001/archgenpsychiatry.2011.12

Murphy, E., Kapur, N., Webb, R., Purandare, N., Hawton, K., Bergen, H., \& Cooper, J. (2012). Risk factors for repetition and suicide following self-harm in older adults: Multicentre cohort study. British Journal of Psychiatry, 200, 399-404. doi:10.1192/bjp.bp.111.094177

Owens, D., Horrocks, J., \& House, A. (2002). Fatal and non-fatal repetition of self-harm. Systematic review. British Journal of Psychiatry, 181, 193-199.

Penney, A., Mazmanian, D., Jamieson, J., \& Black, N. (2012). Factors associated with recent suicide attempts in clients presenting for addiction treatment. International Journal of Mental Health and Addiction, 10, 132-140. doi:10.1007/s11469-010-9307-0

Petry, N. M., \& Kiluk, B. D. (2002). Suicidal ideation and suicide attempts in treatment-seeking pathological gamblers. Journal of Nervous and Mental Disease, 190, 462-469. doi:10.1097/01. NMD.0000022447.27689.96

Petry, N. M., Litt, M. D., Kadden, R., \& Ledgerwood, D. M. (2007). Do coping skills mediate the relationship between cognitive-behavioral therapy and reductions in gambling in pathological gamblers? Addiction, 102, 1280-1291.

Pilver, C. E., Libby, D. J., Hoff, R. A., \& Potenza, M. N. (2013). Problem gambling severity and the incidence of axis I psychopathology among older adults in the general population. Journal of Psychiatric Research, 47, 534-541. doi:10.1016/j.jpsychires.2012.12.013

Sansone, R. A., \& Sansone, L. A. (2010). Measuring self-harm behavior with the self-harm inventory. Psychiatry (1550-5952), 7, 16-20.

Seguin, M., Boyer, R., Lesage, A., McGirr, A., Suissa, A., Tousignant, M., \& Turecki, G. (2010). Suicide and gambling: Psychopathology and treatment-seeking. Psychology of Addictive Behaviors, 24, 541-547. doi:10.1037/A0019041

Skinner, H. A. (1982). The drug abuse screening test. Addictive Behaviors, 7, 363-371. 
Spitzer, R. L., Kroenke, K., \& Williams, J. B. (1999). Validation and utility of a self-report version of PRIME-MD: The PHQ primary care study. Primary care evaluation of Mental Disorders. Patient health questionnaire. JAMA, 282, 1737-1744.

Spitzer, R. L., Williams, J. B., Kroenke, K., Linzer, M., deGruy, F. V.3rdS. R.Hahn, \& Johnson, J. G. (1994). Utility of a new procedure for diagnosing mental disorders in primary care. The PRIMEMD 1000 study. JAMA, 272, 1749-1756.

Tse, S., Hong, S. I., Wang, C. W., \& Cunningham-Williams, R. M. (2012). Gambling behavior and problems among older adults: A systematic review of empirical studies. The Journals of Gerontology Series B: Psychological Sciences and Social Sciences, 67, 639-652. doi:10.1093/geronb/gbs068

Voshaar, R. C. O., Cooper, J., Murphy, E., Steeg, S., Kapur, N., \& Purandare, N. B. (2011). First episode of self-harm in older age: A report from the 10-year prospective Manchester self-harm project. Journal of Clinical Psychiatry, 72, 737-743. doi:10.4088/Jcp.10m06501

Wardle, H. (2007). British gambling prevalence survey 2007. Norwich: The Stationery Office.

Wilcox, H. C., Arria, A. M., Caldeira, K. M., Vincent, K. B., Pinchevsky, G. M., \& O’Grady, K. E. (2012). Longitudinal predictors of past-year non-suicidal self-injury and motives among college students. Psychological Medicine, 42, 717-726. doi:10.1017/S0033291711001814

Woltman, H., Feldstain, A., MacKay, J. C., \& Rocchi, M. (2012). An introduction to hierarchical linear modeling. Tutorials in Quantitative Methods for Psychology, 8, 52-69.

Wong, P. W. C., Chan, W. S. C., Conwell, Y., Conner, K. R., \& Yip, P. S. F. (2010). A psychological autopsy study of pathological gamblers who died by suicide. Journal of Affective Disorders, 120 , 213-216. doi:10.1016/j.jad.2009.04.001

Wong, P. W. C., Cheung, D. Y. T., Conner, K. R., Conwell, Y., \& Yip, P. S. F. (2010). Gambling and completed suicide in Hong Kong: A review of coroner court files. Primary Care Companion to the Journal of Clinical Psychiatry, 12, e1-e7.

Wood, R. T., \& Griffiths, M. D. (2007). Online data collection from gamblers: Methodological issues. International Journal of Mental Health and Addiction, 5, 151-163.

Wood, R. T., \& Williams, R. J. (2007). Problem gambling on the internet: Implications for internet gambling policy in North America. New Media \& Society, 9, 520-542. doi:10.1177/1461444807076987

Young, R., Van Beinum, M., Sweeting, H., \& West, P. (2007). Young people who self-harm. British Journal of Psychiatry, 191, 44-49. doi:10.1192/bjp.bp.106.034330

Yudko, E., Lozhkina, O., \& Fouts, A. (2007). A comprehensive review of the psychometric properties of the Drug Abuse Screening Test. Journal of Substance Abuse Treatment, 32, 189-198. 